\title{
The Application of Response Surface Methodology for Lead Ion Removal from Aqueous Solution Using Intercalated Tartrate-Mg-Al Layered Double Hydroxides
}

\author{
Yamin Yasin, ${ }^{1}$ Maszlin Mohamad, ${ }^{2}$ and Faujan B. H. Ahmad ${ }^{2}$ \\ ${ }^{1}$ INTEC Education College, Universiti Teknologi MARA, 40450 Shah Alam, Malaysia \\ ${ }^{2}$ Faculty of Applied Sciences, Universiti Teknologi MARA, 40450 Shah Alam, Malaysia \\ Correspondence should be addressed to Yamin Yasin; yamin961@salam.uitm.edu.my
}

Received 19 October 2012; Revised 15 January 2013; Accepted 19 January 2013

Academic Editor: Deepak Kunzru

Copyright (C) 2013 Yamin Yasin et al. This is an open access article distributed under the Creative Commons Attribution License, which permits unrestricted use, distribution, and reproduction in any medium, provided the original work is properly cited.

Layered double hydroxide intercalated with tartrate (tartrate-Mg-Al) was used as an adsorbent to remove lead ions from aqueous solutions. The effects of various optimization parameters such as contact time, solution $\mathrm{pH}$, lead ion concentrations, and adsorbent dosage were investigated by the use of Response Surface Methodology (RSM). The Response Surface Methodology (RSM) based on a four-level four-variable Central Composite Rotatable Design (CCRD) was employed to evaluate the interactive effects of the various optimization parameters. The parameters were contact time (6-10 h), solution $\mathrm{pH}(1-3)$, adsorbent dosage $(0.06-0.1 \mathrm{~g})$, and lead ion concentrations $(10-30 \mathrm{mg} / \mathrm{L})$. The percentage of lead ions removal for each of the parameters studied was determined by Inductively Coupled Plasma-Optical Emission Spectrophotometer. Simultaneously by increasing contact time and amount of dosage of tartrate- $\mathrm{Mg}$-Al used the percentage of lead ions removal from aqueous solution will increase; however, the percentage removal decreases with an increase in $\mathrm{pH}$ and concentrations of lead ions. The experimental percentage removal recorded under optimum conditions was compared well with the maximum predicted value from the RSM, which suggest that Central Composite Rotatable Design of RSM can be used to study the removal of lead from aqueous solution by the use of tartrate-Mg-Al as an adsorbent.

\section{Introduction}

The pollution of aqueous solution by high concentrations of metal cations can contribute to a serious environmental problem. The removal of metal cations from aqueous solution to a certain concentration level is therefore becoming an important issue. Adsorption is one of the effective methods to remove metal cations from aqueous solution [1]. Various materials can be used as an adsorbent for the removal of metal cations such as activated carbon [1], biomaterials [2], and clay minerals [3]. In recent years, the use of clay minerals as an adsorbent were found increasing in interest, and numerous studies on the adsorption of metal cations have been carried out by use of the metal oxides [4], metal hydroxides [5], and metal carbonates [6] which are due to their abundance in nature and good metal cations adsorption 1 properties [4-6].
Layered Double Hydroxide (LDH) is one of the clay minerals that have good metal cations adsorption properties with a negatively charged layers, high anion exchange property, and high surface areas. The chemical composition of layered double hydroxides can be described by the formula $\left[\mathrm{M}_{1-x}^{2+} \mathrm{M}_{x}^{3+}(\mathrm{OH})_{2}\right]^{x+}\left(\mathrm{A}^{n-}\right)_{x / n} \cdot m \mathrm{H}_{2} \mathrm{O}$ where $\mathrm{M}^{2+}$ and $\mathrm{M}^{3+}$ are metal cations, for example, $\mathrm{Mg}^{2+}$ and $\mathrm{Al}^{3+}$ that occupy octahedral sites in the hydroxide layers. $\mathrm{A}^{n-}$ is an exchangeable anion, and $x$ is the ratio of $\mathrm{M}^{3+} /\left(\mathrm{M}^{2+}+\mathrm{M}^{3+}\right)$. Carbonates are the interlayer anions in the naturally occurring mineral hydroxides, which is a member of this class of materials.

Several studies have reported on the use of layered double hydroxides as an adsorbent for the preservation of aqueous environments, such as treatment of coloured water $[7,8]$, treatment of water polluted with heavy metals $[9,10]$, and as nitrogen oxide storage [11]. The adsorption 
properties of layered double hydroxides toward metal cations can be improved by intercalating layered double hydroxides with metal chelating agents such as tartrate [5]. Recently several studies on the intercalated compounds of layered double hydroxides, which can be used as an adsorbent for the removal of heavy metals, have been reported. Magnesium aluminium layered double hydroxides intercalated with ethylenediaminetetraacetate (EDTA) have been reported to have successfully taken up heavy metals such as $\mathrm{Cu}^{2+}$ and $\mathrm{Cd}^{2+}$ from aqueous solution and the formation of EDTAmetal complex in the interlayer of layered double hydroxide was to be believed as the principal mechanism for the removal [9]. Similar study was also reported in the use of intercalated EDTA-zinc-aluminium layered double hydroxides for the removal of heavy metals of $\mathrm{Cu}^{2+}, \mathrm{Cd}^{2+}$, and $\mathrm{Pb}^{2+}[10]$.

Response Surface Methodology (RSM) is an effective statistical technique, which provides an investigative approach towards optimization. In addition, it is a collection of mathematical and statistical techniques used in significance of several affecting factors in an optimum manner, even in the presence of complex interactions [12]. The main reason for implementing RSM is to determine the optimum operational conditions for the process or to determine a region that satisfies the operating specifications [13]. The limitations posed by conventional analytical optimization method can be eliminated by optimizing all the affecting parameters collectively using RSM. In our present study, RSM comprises of a four-level four-factor Central Composite Rotatable Design (CCRD), which was used to evaluate the interactive effects and to obtain the optimum conditions for lead ions removal from aqueous solutions using intercalated tartrate-Mg-Al layered double hydroxide.

\section{Experimental}

2.1. Synthesis of Tartrate-Mg-Al Layered Double Hydroxide (Tartrate- $M g-A l)$. All chemicals used in this synthesis were of analytical grade and used without any purification. The coprecipitation method was adapted to synthesize tartrate-Mg-Al layered double hydroxides in this work. In the preparation of $\mathrm{Mg}-\mathrm{Al}$ solution, an aqueous solution of $\mathrm{Mg}\left(\mathrm{NO}_{3}\right)_{2} \cdot 6 \mathrm{H}_{2} \mathrm{O}$ and $\mathrm{Al}\left(\mathrm{NO}_{3}\right)_{3} \cdot 9 \mathrm{H}_{2} \mathrm{O}$ was dissolved in deionized water to give $\mathrm{Mg}^{2+} / \mathrm{Al}^{3+}$ ratio of 4 . The tartrate solutions were prepared by dissolving the required amount of organic salt of tartrate in deionized water according to the stoichiometric quantities defined by the following equation [5]:

$$
\begin{gathered}
0.2 \mathrm{Mg}^{2+}+0.05 \mathrm{Al}^{3+}+0.1 \mathrm{C}_{4} \mathrm{H}_{4} \mathrm{O}_{6}{ }^{2-}+2 \mathrm{OH}^{-} \\
\longrightarrow \mathrm{Mg}_{0.2} \mathrm{Al}_{0.05}(\mathrm{OH})_{2}\left(\mathrm{C}_{4} \mathrm{H}_{4} \mathrm{O}_{6}\right)_{0.1}
\end{gathered}
$$

An aqueous solution of $\mathrm{Mg}-\mathrm{Al}-\mathrm{NO}_{3}$ at a ratio of 4 was then added dropwise to a solution of tartrate under nitrogen atmosphere with vigorous stirring. The solution mixture was kept under nitrogen atmosphere throughout the synthesis process to minimize the effects of dissolved carbon dioxide. The $\mathrm{pH}$ of the solution mixture was kept constants at a $\mathrm{pH}$ of 10 by adding a sodium hydroxide solution. The resulting
TABLE 1: The level and range of independent variables chosen for removal of lead from aqueous solution using tartrate-Mg-Al layered double hydroxide.

\begin{tabular}{lcccc}
\hline Factor & Variable & Unit & $\begin{array}{c}\text { Range and level of actual and } \\
\text { coded values }\end{array}$ \\
& & & Low actual $(-1)$ & High actual $(+1)$ \\
\hline$A$ & Time & hour & 6 & 10 \\
$B$ & $\mathrm{pH}$ & - & 1 & 3 \\
$C$ & Dosage & $\mathrm{mg}$ & 0.06 & 0.1 \\
$D$ & Concentration & $\mathrm{mg} / \mathrm{L}$ & 10 & 30 \\
\hline
\end{tabular}

slurry was aged at $70^{\circ} \mathrm{C}$ for 24 hours in an oil batch shaker and was then filtered and washed with deionized water to remove free ions and excess organic salt. The material was then dried in an oven at $60^{\circ} \mathrm{C}$ for 24 hours and was kept in sample bottles for further use and characterizations.

2.2. Characterization of Original $M g$-Al Layered Double Hydroxide $\left(\mathrm{Mg}-\mathrm{Al}-\mathrm{NO}_{3}\right)$ and Tartrate- $\mathrm{Mg}$-Al Layered Double Hydroxide (Tartrate- $M g-A l$ ). The X-ray Diffraction (XRD) patterns of $\mathrm{Mg}-\mathrm{Al}-\mathrm{NO}_{3}$ and tartrate- $\mathrm{Mg}-\mathrm{Al}$ layered double hydroxide before and after removal experiments were obtained by PANlytical X'pert Pro using Ni-filtered $\mathrm{Cu}_{\alpha}$ radiation, $60 \mathrm{KV}$, and $60 \mathrm{~mA}$. The basal spacing ( $d$-spacing) of the compounds was determined via powder technique. All solid samples were mounted on PW18xx sample holder series, and the scans were done at $5^{\circ}-90^{\circ}$ over $2 \theta / \mathrm{min}$ at $0.003^{\circ}$ steps.

2.3. Experimental Design. A four-level four-factor CCRD design was employed in this study, leading to a set of 15 experiments. The variables and their levels selected for the study of the removal of lead ions using tartrate- $\mathrm{Mg}$-Al layered double hydroxide were contact time $(6-10 \mathrm{~h})$, adsorbent dosage (0.06-0.1 g), solution $\mathrm{pH}(1-3)$, and lead ion concentrations $(10-30 \mathrm{mg} / \mathrm{L})$, based on the preliminary experiments using conventional optimization method as shown in Table 1 . The variables and their respective levels are presented in Table 2, which represents the actual experiments (in triplicate) carried out for developing the model. The data obtained were fitted to a second-order polynomial equation:

$$
y=\beta_{0}+\sum_{i=1}^{4} \beta_{i} x_{i}+\sum_{i=1}^{4} \beta_{i i} x^{2}+\sum_{i=1}^{3} \sum_{j=1+1}^{4} \beta_{i j} x_{i_{j}},
$$

where $Y$ is percentage of lead ions removed; $\beta_{0}, \beta_{i}, \beta_{i i}, \beta_{i j}$ are constant coefficients $x_{i}$ are the uncoded independent variables. Subsequent regression analyses, analyses of variance (ANOVA) and response surfaces were performed using the Design Expert Software (Version 6.0.4) from Stat-Ease Inc. (Minneapolis, MN, USA). Optimal reaction parameters for maximum removal were generated using the software's numerical optimization function.

2.4. Batch Adsorption and Analysis. Batch method was employed in the removal experiment of lead ions from aqueous solution using tartrate- $\mathrm{Mg}$-Al layered double hydroxides 
TABLE 2: Central composite rotatable quadratic polynomial model, experimental data, and actual and predicted values for five-level four-factor response surface analysis.

\begin{tabular}{|c|c|c|c|c|c|c|}
\hline Run & $A$ & $B$ & $C$ & $D$ & $\begin{array}{c}\text { Actual } \\
\text { (\% Removal) }\end{array}$ & $\begin{array}{c}\text { Predicted } \\
\text { (\% Removal) }\end{array}$ \\
\hline 1 & 10 & 2.5 & 0.08 & 30 & 99.13 & 99.22 \\
\hline 2 & 8 & 3.5 & 0.06 & 40 & 97.15 & 102.21 \\
\hline 3 & 12 & 3.5 & 0.1 & 20 & 98.38 & 95.77 \\
\hline 4 & 10 & 2.5 & 0.08 & 30 & 99.23 & 99.22 \\
\hline 5 & 8 & 3.5 & 0.06 & 20 & 99.05 & 106.87 \\
\hline 6 & 12 & 1.5 & 0.1 & 20 & 95.14 & 91.06 \\
\hline 7 & 10 & 2.5 & 0.08 & 30 & 99.23 & 99.22 \\
\hline 8 & 10 & 2.5 & 0.04 & 30 & 73.15 & 56.46 \\
\hline 9 & 10 & 2.5 & 0.08 & 30 & 99.23 & 99.22 \\
\hline 10 & 10 & 0.5 & 0.08 & 30 & 3.4 & 7.40 \\
\hline 11 & 10 & 2.5 & 0.08 & 50 & 91.8 & 90.49 \\
\hline 12 & 10 & 2.5 & 0.08 & 30 & 99.24 & 99.22 \\
\hline 13 & 6 & 2.5 & 0.08 & 30 & 97.48 & 95.01 \\
\hline 14 & 12 & 3.5 & 0.06 & 40 & 99.23 & 105.57 \\
\hline 15 & 10 & 2.5 & 0.12 & 30 & 98.85 & 111.33 \\
\hline 16 & 12 & 1.5 & 0.06 & 20 & 24.64 & 30.28 \\
\hline 17 & 10 & 4.5 & 0.08 & 30 & 98.77 & 90.56 \\
\hline 18 & 8 & 1.5 & 0.1 & 20 & 95.14 & 92.03 \\
\hline 19 & 12 & 1.5 & 0.1 & 40 & 96.71 & 92.12 \\
\hline 20 & 8 & 1.5 & 0.06 & 20 & 30.25 & 30.70 \\
\hline 21 & 10 & 2.5 & 0.08 & 30 & 99.23 & 99.22 \\
\hline 22 & 14 & 2.5 & 0.08 & 30 & 99.14 & 97.40 \\
\hline 23 & 10 & 2.5 & 0.08 & 10 & 96.98 & 94.08 \\
\hline 24 & 8 & 3.5 & 0.1 & 40 & 98.72 & 96.31 \\
\hline 25 & 8 & 1.5 & 0.06 & 40 & 17.94 & 23.77 \\
\hline 26 & 8 & 3.5 & 0.1 & 20 & 97.97 & 98.19 \\
\hline 27 & 8 & 1.5 & 0.1 & 40 & 92.58 & 87.88 \\
\hline 28 & 12 & 1.5 & 0.06 & 40 & 27.81 & 28.58 \\
\hline 29 & 12 & 3.5 & 0.1 & 40 & 98.57 & 99.11 \\
\hline 30 & 12 & 3.5 & 0.06 & 20 & 99.32 & 105.01 \\
\hline
\end{tabular}

A: time (h); B: pH; C: dosage (mg); D: concentration (mg/L).

(tartrate-Mg-Al). A sample of $0.05 \mathrm{~g}$ tartrate- $\mathrm{Mg}-\mathrm{Al}$ was placed in a $100 \mathrm{~mL}$ Schott Duran bottles, and $25 \mathrm{~mL}$ of $20-$ $40 \mathrm{mg} / \mathrm{L}$ lead solution was added to the bottles and agitated by the use of shaker operating at room temperature with a speed of $150 \mathrm{rpm}$. The amount of lead ions removed (\%) was calculated as

$$
\frac{C_{0}-C_{t}}{C_{0}} \times 100 \%,
$$

where $C_{0}$ is the initial concentration $(\mathrm{mM})$ of the lead ions solution and $C_{t}$ is the concentration at equilibrium at the time $t$. At predetermined time, $5 \mathrm{~mL}$ of the solutions were withdrawn and filtered through $0.45 \mu \mathrm{m}$ Whatman syringe filter. The remaining concentration of lead ions was then measured by using Perkin Elmer Optima 8300 Inductive

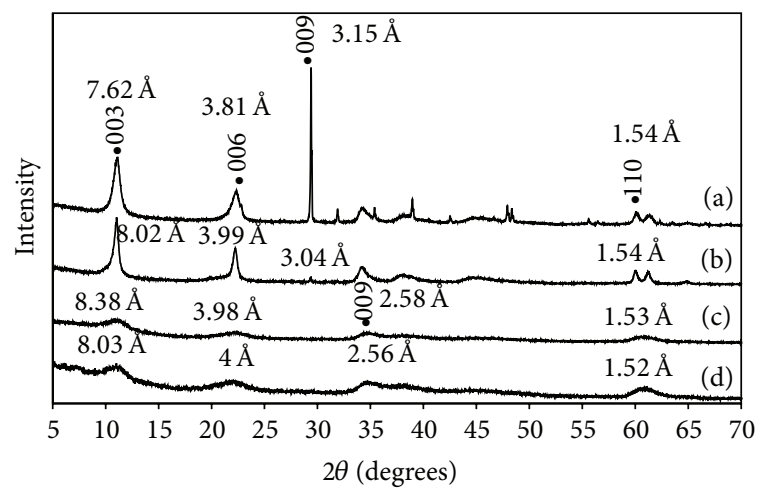

Figure 1: XRD patterns of (a) original Mg-Al- $\mathrm{NO}_{3}$, (b) $\mathrm{Mg}-\mathrm{Al}-\mathrm{NO}_{3}$ $\mathrm{Pb},(\mathrm{c})$ tartrate $\mathrm{Mg}-\mathrm{Al}$ and $(\mathrm{d})$ tartrate- $\mathrm{Mg}-\mathrm{Al}-\mathrm{Pb}$.

Coupled Plasma-Optical Emission Spectrophotometer (ICPOES). All experiments were conducted in duplicate, and controls were simultaneously carried out to ensure that the removal was by the adsorbent and not by the wall of the glassware. In order to avoid precipitation, the $\mathrm{pH}$ of the solution was kept below than 6 since the solubility product of $\mathrm{Pb}(\mathrm{OH})_{2}$ is recorded at $1.43 \times 10^{-20}$ [14].

\section{Results and Discussion}

3.1. Characterization of Original $M g-A l$ Layered Double Hydroxide $\left(\mathrm{Mg}-\mathrm{Al}-\mathrm{NO}_{3}\right)$ and Tartrate- $\mathrm{Mg}$-Al Layered Double Hydroxide (Tartrate- $M g-A l)$. The structure of layered double hydroxides $\left(\mathrm{Mg}-\mathrm{Al}-\mathrm{NO}_{3}\right)$ synthesized at a ratio of 4 and the structures of intercalated compound before (tartrate$\mathrm{Mg}-\mathrm{Al}$ ) and after removal of lead (tartrate-Mg-Al-Pb) ions were characterized, and their XRD patterns were shown in Figure 1. As shown in Figure 1(a), original layered double hydroxides $\left(\mathrm{Mg}-\mathrm{Al}-\mathrm{NO}_{3}\right)$ indicate fairly good crystallinity. This was proved by the $d$-spacing recorded at $7.6 \AA$ that demonstrated general features of layered double hydroxides [15-17]. The $d$-spacing shows the characteristic values for trigonal structures with a strong sharp and symmetrical peaks assigned to (003) and (006) planes, respectively. The interlayer spacing of the sample corresponding to the (006) plane was found to be $3.8 \AA$.

The original XRD patterns of tartrate-Mg-Al (Figure $1(\mathrm{c})$ ) show broader in patterns as compared to the original $\mathrm{Mg}$ $\mathrm{Al}-\mathrm{NO}_{3}$ which suggest that tartrate-Mg-Al had the common structure of the $\mathrm{Mg}-\mathrm{Al}-\mathrm{NO}_{3}$. The basal spacing for tartrate$\mathrm{Mg}-\mathrm{Al}$ recorded at $8.38 \AA$ indicates that the interlayer spacing was larger than that of the $\mathrm{Mg}-\mathrm{Al}-\mathrm{NO}_{3}$. The pattern reveals that the intercalation of tartrate ions in the interlayer of $\mathrm{Mg}$ $\mathrm{Al}-\mathrm{NO}_{3}$ increased the basal spacing from $7.6 \AA$ to $8.38 \AA$. The basal spacing recorded for the tartrate- $\mathrm{Mg}$-Al suggests that the tartrate ions which are larger than the nitrate ions were intercalated into the interlayer of $\mathrm{Mg}-\mathrm{Al}-\mathrm{NO}_{3}$ layered double hydroxides [5]. The XRD patterns of tartrate-Mg-Al$\mathrm{Pb}$ after removal of lead ions (Figure $1(\mathrm{~d})$ ) show the basal spacing which is slightly lower than that of original tartrateMg-Al. The pattern shows no additional peaks detected 
TABLE 3: ANOVA for removal of lead from aqueous solution using tartrate-Mg-Al layered double hydroxide.

\begin{tabular}{lccccc}
\hline Source & $\begin{array}{c}\text { Degree of } \\
\text { freedom }\end{array}$ & $\begin{array}{c}\text { Sum of } \\
\text { squares }\end{array}$ & $\begin{array}{c}\text { Mean } \\
\text { square }\end{array}$ & $F$ value & $P$ \\
\hline Model & 14 & 24350.42 & 1739.32 & 30.86 & $<0.0010$ \\
Residual & 15 & 845.43 & 56.36 & & \\
Lack of fit & 10 & 845.42 & 84.54 & 48309.97 & $<0.0010$ \\
Pure error & 5 & 0.00875 & 0.00175 & & \\
Total & 29 & 25195.86 & & & \\
Time $(A)$ & 1 & 8.54 & 8.54 & 0.15 & 0.7025 \\
pH $(B)$ & 1 & 10371.72 & 10371.72 & 184.02 & $<0.0010$ \\
Dosage $(C)$ & 1 & 4516.08 & 4516.08 & 80.13 & $<0.0010$ \\
Concentration & 1 & 19.33 & 19.33 & 0.34 & 0.5668 \\
$(D)$ & 1 & & & & \\
\hline
\end{tabular}

for precipitation products of lead which indicates that the main mechanism for the removal of lead ion is not through the surface precipitation reaction between lead ions and hydroxide ions. Therefore, the result suggests that the main mechanism for the removal of lead is through the formation of metal complexes between the lead ions and the tartrates which are formed in the interlayer of tartrate-Mg-Al layered double hydroxides.

3.2. Model Development. The coefficients of the empirical model and their statistical analyses, evaluated using the Design Expert Software, are presented in Table 3. The predicted values were obtained from the model-fitting technique using the Design Expert Software version 6.0.4 and were seen to be sufficiently correlated with the observed values. Fitting of the data to various models (linear, two factorial, quadratic, and cubic) and their subsequent ANOVA showed that the removal of lead ions from aqueous solution using tartrateMg-Al layered double hydroxide was suitably described by quadratic model. From the Design Expert Software, the quadratic polynomial is given as follows:

$$
\begin{aligned}
\text { Removal }(\%)= & 99.22+0.60 A+20.79 B+13.72 C \\
& -0.90 D-0.75 A^{2}-12.56 B^{2} \\
& -3.83 C^{2}-1.73 D^{2}-0.36 A B \\
& -0.14 A C+1.30 A D-17.50 B C \\
& +0.57 B D+0.69 C D
\end{aligned}
$$

where $A$ is contact time, $B$ is solution $\mathrm{pH}, C$ is the amount of dosage, and $D$ is the concentration.

The computed model $F$-value of 30.86 was higher than the tabular value implying that the model is significant at $1 \%$ confidence level. There is only a $0.01 \%$ chance that the model $F$-value large could occur due to noise. The model also showed a very low value of pure error of 0.0087 , which indicates good reproducibility of the data obtained. The values of "Prob > F" less than 0.0500 indicate the significance of the model. Based on the analyzed results, the

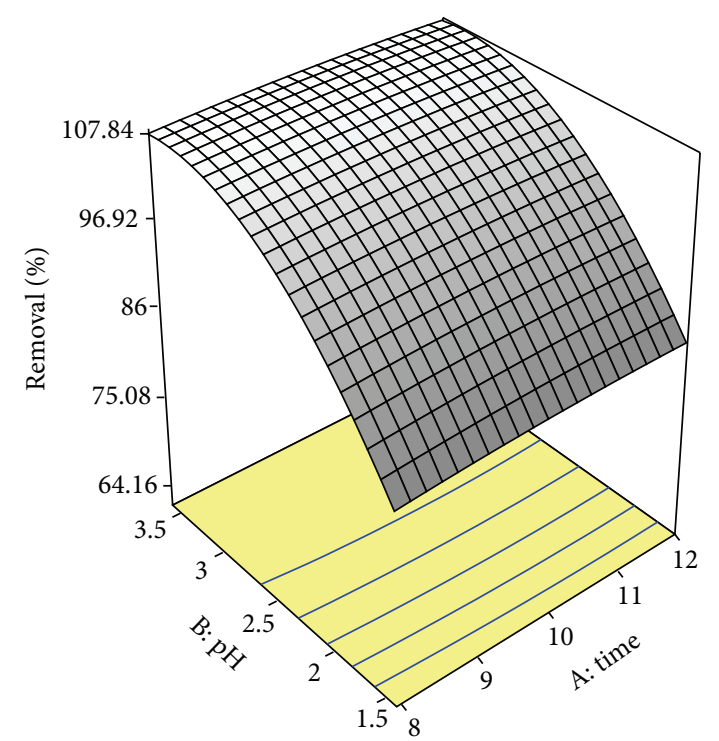

FIGURE 2: Response surface plot showing the effect of contact time and $\mathrm{pH}$ and their mutual effect on the removal of lead using tartrate$\mathrm{Mg}$-Al layered double hydroxide.

solution $\mathrm{pH}$, the adsorbent dosage, and the combination of $\mathrm{pH}$ and adsorbent dosage are significant model terms. The high coefficient of determination $\left(R^{2}=0.9664\right)$ showed that the quadratic polynomial was highly significant and sufficient to represent the actual relationship between the removal (\%) and the significant variables.

3.3. Response Surface Plots. The quadratic polynomial equation was then used to facilitate plotting of response surfaces. Two parameters were plotted at any one time on the $x_{1}$ and $x_{2}$ axes, respectively, with the other remaining parameters set at their center points values (coded level: 0). Figure 2 shows the profile of contact time versus $\mathrm{pH}$ of lead solution for removal of lead ions from aqueous solution using tartrate$\mathrm{Mg}$-Al layered double hydroxide. A response surface plot for interaction between contact time and $\mathrm{pH}$ of lead solution was generated with the parameters of amount of dosage and concentrations fixed at center points of $(0.05 \mathrm{~g})$ and $(30 \mathrm{mg} / \mathrm{L})$, respectively, under any given conditions. From Figure 2, at any given $\mathrm{pH}$ of lead solutions from 1 to 3 , an increase in contact time led to a higher percentage removal. An increase in $\mathrm{pH}$ up to 10 resulted in a decrease in percentage removal of lead ions. The metal cations in layered double hydroxides layers begin to dissolve at high $\mathrm{pH}$, which resulted in the decrease of lead removal at high $\mathrm{pH}$. Removal of lead from aqueous solution using tartrate-Mg-Al layered double hydroxide as an adsorbent with moderate $\mathrm{pH}$ and maximum contact time favored maximal percentage removal.

Response surface predicted, the interaction of contact time, and amount of adsorbent dosage are illustrated in Figure 3 with the concentration of lead solution set at center point value of $30 \mathrm{mg} / \mathrm{L}$. As shown in Figure 3, at any given amount of layered double hydroxide dosage from 0.06 to $0.1 \mathrm{~g}$, an increase in contact time led to a higher percentage 


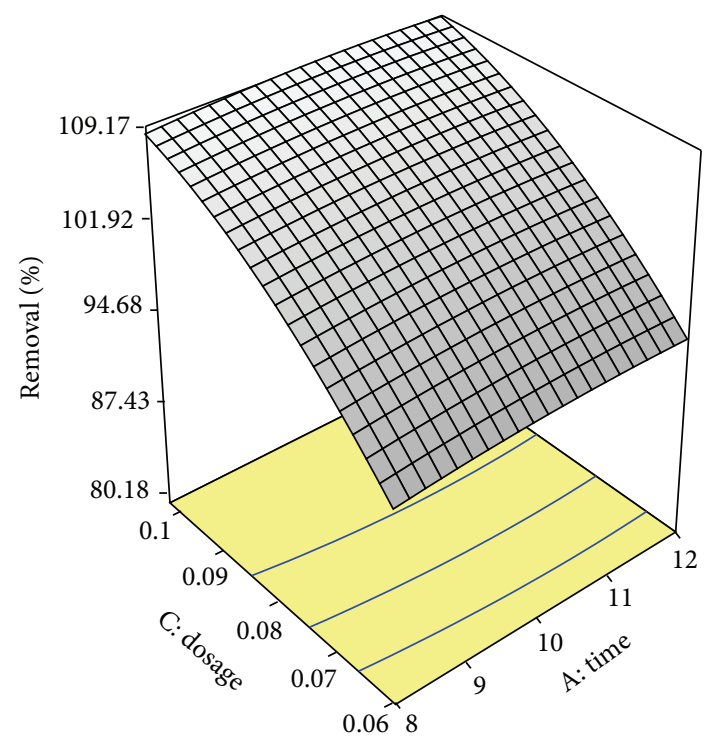

FIGURE 3: Response surface plot showing the effect of contact time and amount of dosage and their mutual effect on the removal of lead using tartrate-Mg-Al layered double hydroxide.

removal of lead ions. Removal with the highest dosage and highest contact time favored maximal percentage removal. The similar trend of profile in contact time versus amount of dosage also has been previously found and has indeed been reported $[18,19]$.

The response surface presented in Figure 4 shows the effect of contact time and concentration of lead solution at a fixed $\mathrm{pH}$ and adsorbent dosage on the percentage removal of lead using tartrate- $\mathrm{Mg}-\mathrm{Al}$ layered double hydroxide. As shown in Figure 4, adsorption at the highest contact time and low concentration of lead solution favors maximum percentage removal. The percentage removal of lead decreases with increasing concentrations of lead solution. This explains a common observation that the percentage removal of lead is decreased due to the limiting amount of tartrate-Mg-Al dosage used that could inhibit the formation of complexes between tartrate and lead ions with an increase in concentrations of lead solution. This can be attributed to the decrease in the area for the formation of complexes with the increase of lead solution concentration. Figures 5 and 6 present the response surface plots as functions of $\mathrm{pH}$ versus lead solution concentration and $\mathrm{pH}$ versus dosage of tartrate$\mathrm{Mg}-\mathrm{Al}$ layered double hydroxide, respectively. As expected, the percentage removal of lead is maximized at the highest lead concentrations and moderate $\mathrm{pH}$.

Figure 7 presents the effect of varying the lead ion concentrations and the tartrate-Mg-Al dosages. At low dosages and low concentrations of lead solution, the percentage removal of lead was lower, and this was attributed to a limited affective area for the formation of complexes between lead and tartrate ions and the decrease in probability of lead ions to find a site for the formation of complexes. Higher percentage removal is achieved with high amounts of tartrate-Mg-Al and high concentrations of lead solution, because larger

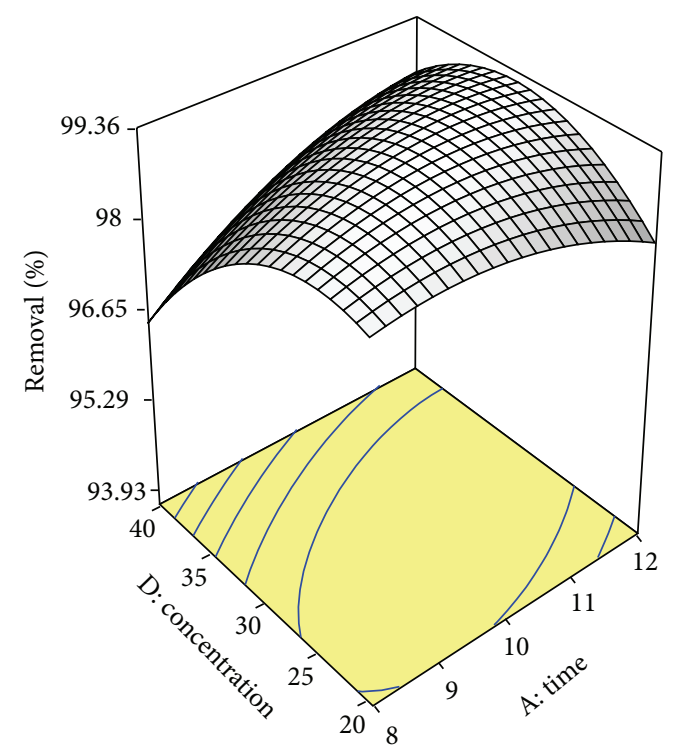

FIGURE 4: Response surface plot showing the effect of contact time and concentration of lead and their mutual effect on the removal of lead using tartrate-Mg-Al layered double hydroxide.

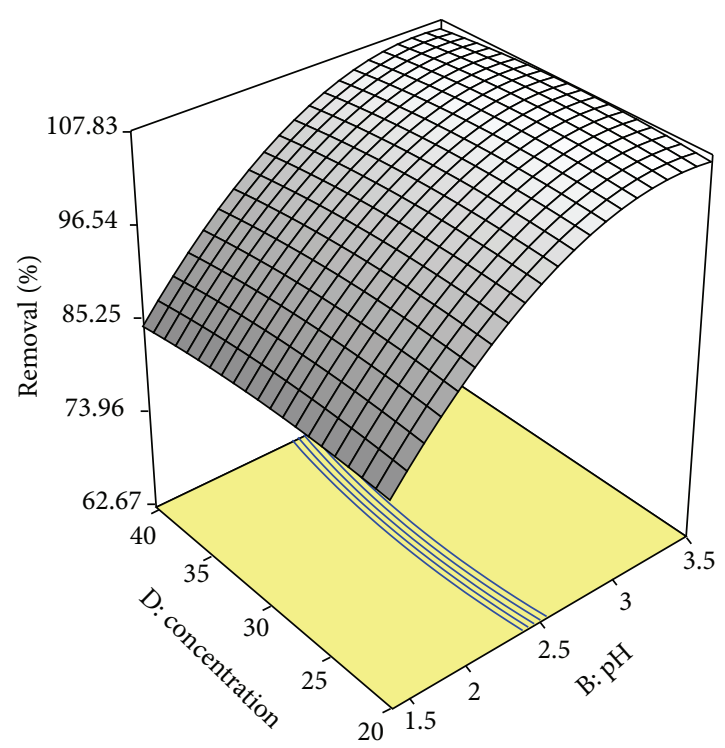

FIGURE 5: Response surface plot showing the effect of $\mathrm{pH}$ and concentration of lead and their mutual effect on the removal of lead using tartrate-Mg-Al layered double hydroxide.

quantities of lead ions increase the ratio of the adsorbate to adsorbent thus promoting the formation of complexes as well as increasing the percentage removal.

3.4. Optimum Conditions. Within the experimental range studied, the optimum conditions for lead ion removal using tartrate-Mg-Al have been predicted using Design Expert's optimization function. The optimum conditions are presented in Table 3 along with their predicted and actual values. The analysis indicates that a maximum percentage removal 


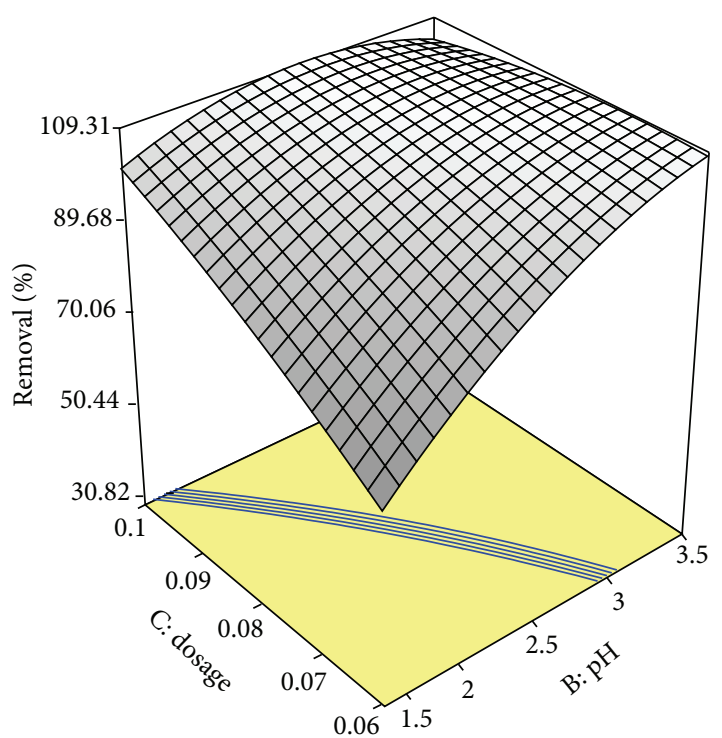

FIGURE 6: Response surface plot showing the effect of $\mathrm{pH}$ and amount of dosage and their mutual effect on the removal of lead using tartrate-Mg-Al layered double hydroxide.

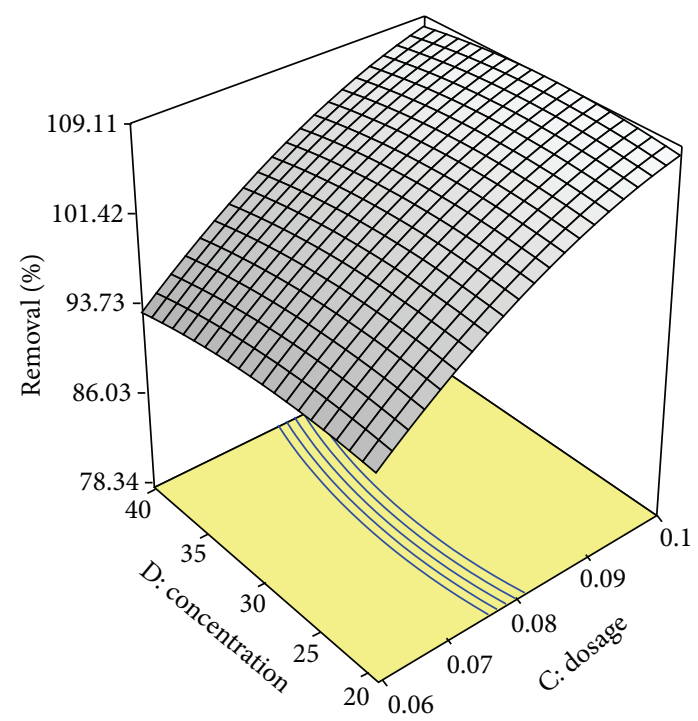

FIGURE 7: Response surface plot showing the effect concentration of lead and amount of dosage and their mutual effect on the removal of lead using tartrate-Mg-Al layered double hydroxide.

of lead ion requires a contact time of 7.98 hours, an initial concentration of $40.09 \mathrm{mg} / \mathrm{L}$, adsorbent dosage of $0.06 \mathrm{~g}$, and a $\mathrm{pH}$ of 3.52 . The predicted and experimental percentage removal values of $99.22 \%$ and $98.32 \%$ under these conditions are in good agreement, implying that the empirical model derived by RSM could be used adequately to describe the relationship between the factors and response with respect to the removal of lead ions using tartrate-Mg-Al layered double hydroxide. The results of the study were supported by previously reported paper on the optimization of lead removal from aqueous solution using specific adsorbents
TABLE 4: Predicted removal from the design experiments for the removal of lead by the use of other adsorbents.

\begin{tabular}{lc}
\hline Adsorbents & Predicted removal \\
\hline Immobilized Pycnoporus sanguineus & $97.7 \%$ \\
Biomass of Aeromonas hydrophila & $98.6 \%$ \\
Polyvinyl alcohol semi-IPN poly(acrylic & $68-69 \%$ \\
acid)/tourmaline composite & \\
\hline
\end{tabular}

[20-22]. As shown in Table 4, the predicted and experimental percentage removals of lead from the design experiments are in agreement, which was implying that the model can be used adequately to study the removal of lead from aqueous solution using other adsorbents.

\section{Conclusion}

The adequacy of the predicted model was evaluated by performing additional independent experiments using suggested optimal removal conditions. From the data obtained, the observed values were statistically near the predicted values, and hence it can be concluded that the generated model adequately predicted the percentage removal. The removal of lead using tartrate-Mg-Al layered double hydroxide has been successfully described through the development of a model using Response Surface Methodology fractional factorial design.

\section{Nomenclature}

$C_{0}$ : Initial concentration of lead ion solution

$C_{t}: \quad(\mathrm{mg} / \mathrm{L})$

desired time $t,(\mathrm{mg} / \mathrm{L})$

$x_{i}: \quad$ Uncoded independent variables

$Y: \quad$ Predicted response

A: $\quad$ Time

B: $\quad$ pH

$C: \quad$ Dosage

$D: \quad$ Initial concentration

Exp.: Experimental value

Pred.: Predicted value

ANOVA: Analysis of variance.

Greek Letters

$\beta_{0}$ : Offset term

$\beta_{i}$ : Linear effect

$\beta_{i i}$ : Squared effect

$\beta_{i j}$ : Interaction effect.

\section{Acknowledgment}

The authors thank Universiti Teknologi MARA for financial support under Excellent Research Grant Scheme. 


\section{References}

[1] J. P. Chen and S. Wu, "Acid/base-treated activated carbons: characterization of functional groups and metal adsorptive properties," Langmuir, vol. 20, no. 6, pp. 2233-2242, 2004.

[2] V. K. Gupta, A. Rastogi, V. K. Saini, and N. Jain, "Biosorption of copper(II) from aqueous solutions by Spirogyra species," Journal of Colloid and Interface Science, vol. 296, no. 1, pp. 59-63, 2006.

[3] J. U. K. Oubagaranadin and Z. V. P. Murthy, "Isotherm modeling and batch adsorber design for the adsorption of $\mathrm{Cu}(\mathrm{II})$ on a clay containing montmorillonite," Applied Clay Science, vol. 50, no. 3, pp. 409-413, 2010.

[4] M. Hua, S. Zhang, B. Pan, W. Zhang, L. Lv, and Q. Zhang, "Heavy metal removal from water/wastewater by nanosized metal oxides," Journal of Hazardous Materials, vol. 211, pp. 317331, 2012.

[5] T. Kameda, H. Takeuchi, and T. Yoshioka, "Uptake of heavy metal ions from aqueous solution using $\mathrm{Mg}-\mathrm{Al}$ layered double hydroxides intercalated with citrate, malate, and tartrate," Separation and Purification Technology, vol. 62, no. 2, pp. 330-336, 2008.

[6] A. Sdiri, T. Higashi, T. Hatta, F. Jamoussi, and N. Tase, "Evaluating the adsorptive capacity of montmorillonitic and calcareous clays on the removal of several heavy metals in aqueous systems," Chemical Engineering Journal, vol. 172, no. 1, pp. 37-46, 2011.

[7] Yasin, A. H. Abdul Malik, S. M. Sumari, and F. B. H. Ahmad, "Removal of amido black dye from aqueous solution by uncalcined and calcined hydrotalcite," Research Journal of Chemistry and Environment, vol. 14, no. 1, pp. 78-84, 2010.

[8] Y. Yasin, A. H. Abdul Malik, and S. M. Sumari, "Adsorption of eriochrome black dye from aqueous solution onto anionic layered double hydroxides," Oriental Journal of Chemistry, vol. 26, no. 4, pp. 1293-1298, 2010.

[9] T. Kameda, S. Saito, and Y. Umetsu, "Mg-Al layered double hydroxide intercalated with ethylene-diaminetetraacetate anion: synthesis and application to the uptake of heavy metal ions from an aqueous solution," Separation and Purification Technology, vol. 47, no. 1-2, pp. 20-26, 2005.

[10] D. Zhao, G. Sheng, J. Hu, C. Chen, and X. Wang, "The adsorption of $\mathrm{Pb}$ (II) on $\mathrm{Mg}_{2} \mathrm{Al}$ layered double hydroxide," Chemical Engineering Journal, vol. 171, no. 1, pp. 167-174, 2011.

[11] J. Cheng, X. Wang, C. Ma, and Z. Hao, "Novel Co-Mg-Al-Ti$\mathrm{O}$ catalyst derived from hydrotalcite-like compound for NO storage/decomposition," Journal of Environmental Science, vol. 24, no. 3, pp. 488-493, 2012.

[12] K. Ravikumar, S. Krishnan, S. Ramalingam, and K. Balu, "Optimization of process variables by the application of response surface methodology for dye removal using a novel adsorbent," Dyes and Pigments, vol. 72, no. 1, pp. 66-74, 2007.

[13] R. H. Myers and D. C. Montgomery, Response Surface Methodology, John Wiley and Sons, 2nd edition, 2001.

[14] Q. Liu and Y. Liu, "Distribution of $\mathrm{Pb}$ (II) species in aqueous solutions," Journal of Colloid and Interface Science, vol. 268, no. 1, pp. 266-269, 2003.

[15] F. Cavani and F. Trifirò, "Hydrotalcite-type anionic clays: preparation, properties and applications," Catalysis Today, vol. 11, no. 2, pp. 173-301, 1991.

[16] M. Bellotto, B. Rebours, O. Clause, J. Lynch, D. Bazin, and E. Elkaïm, "A reexamination of hydrotalcite crystal chemistry,"
Journal of Physical Chemistry, vol. 100, no. 20, pp. 8527-8534, 1996.

[17] K. Chibwe and W. Jones, "Intercalation of organic and inorganic anions into layered double hydroxides," Journal of the Chemical Society, Chemical Communications, no. 14, pp. 926-927, 1989.

[18] K. Ravikumar, K. Pakshirajan, T. Swaminathan, and K. Balu, "Optimization of batch process parameters using response surface methodology for dye removal by a novel adsorbent," Chemical Engineering Journal, vol. 105, no. 3, pp. 131-138, 2005.

[19] Y. Yasin, A. H. Abdul Malek, and F. H. Ahmad, "Response surface methodology study on removal of humic acid from aqueous solutions using anionic clay hydrotalcite," Journal of Applied Sciences, vol. 10, no. 19, pp. 2297-2303, 2010.

[20] Y. Yus Azila, M. D. Mashitah, and S. Bhatia, "Process optimization studies of lead $(\mathrm{Pb}(\mathrm{II}))$ biosorption onto immobilized cells of Pycnoporus sanguineus using response surface methodology," Bioresource Technology, vol. 99, no. 18, pp. 8549-8552, 2008.

[21] S. H. Hasan, P. Srivastava, and M. Talat, "Biosorption of $\mathrm{Pb}(\mathrm{II})$ from water using biomass of Aeromonas hydrophila: central composite design for optimization of process variables," Journal of Hazardous Materials, vol. 168, no. 2-3, pp. 1155-1162, 2009.

[22] Y. Zheng and A. Wang, "Removal of heavy metals using polyvinyl alcohol semi-IPN poly(acrylic acid)/tourmaline composite optimized with response surface methodology," Chemical Engineering Journal, vol. 162, no. 1, pp. 186-193, 2010. 

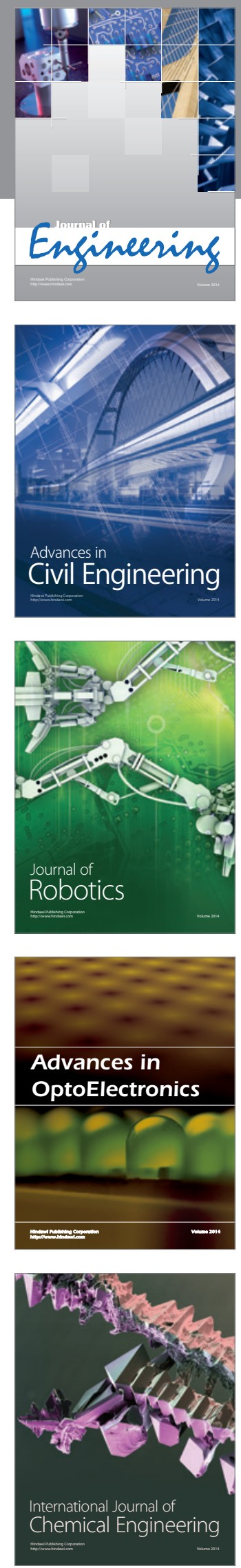

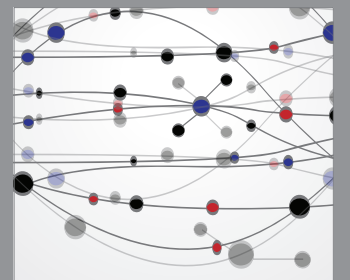

The Scientific World Journal
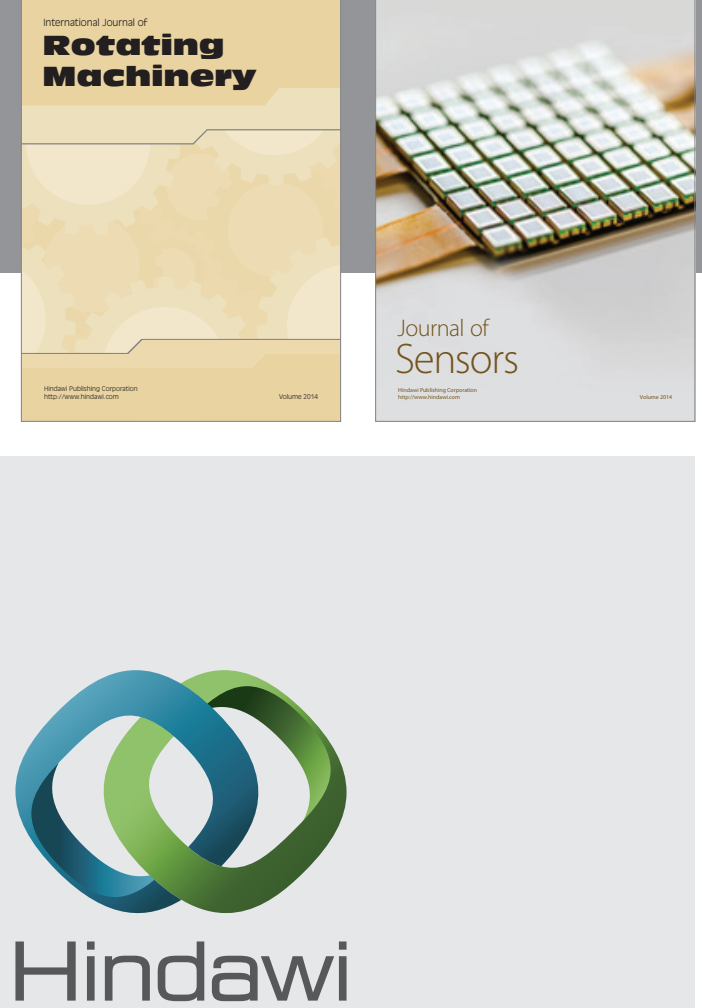

Submit your manuscripts at http://www.hindawi.com
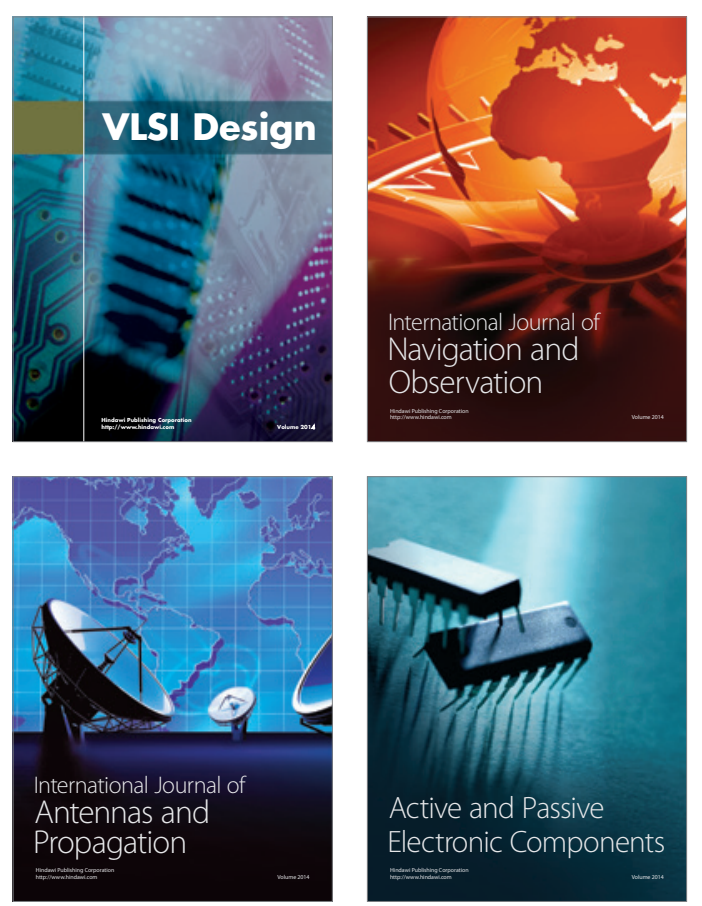
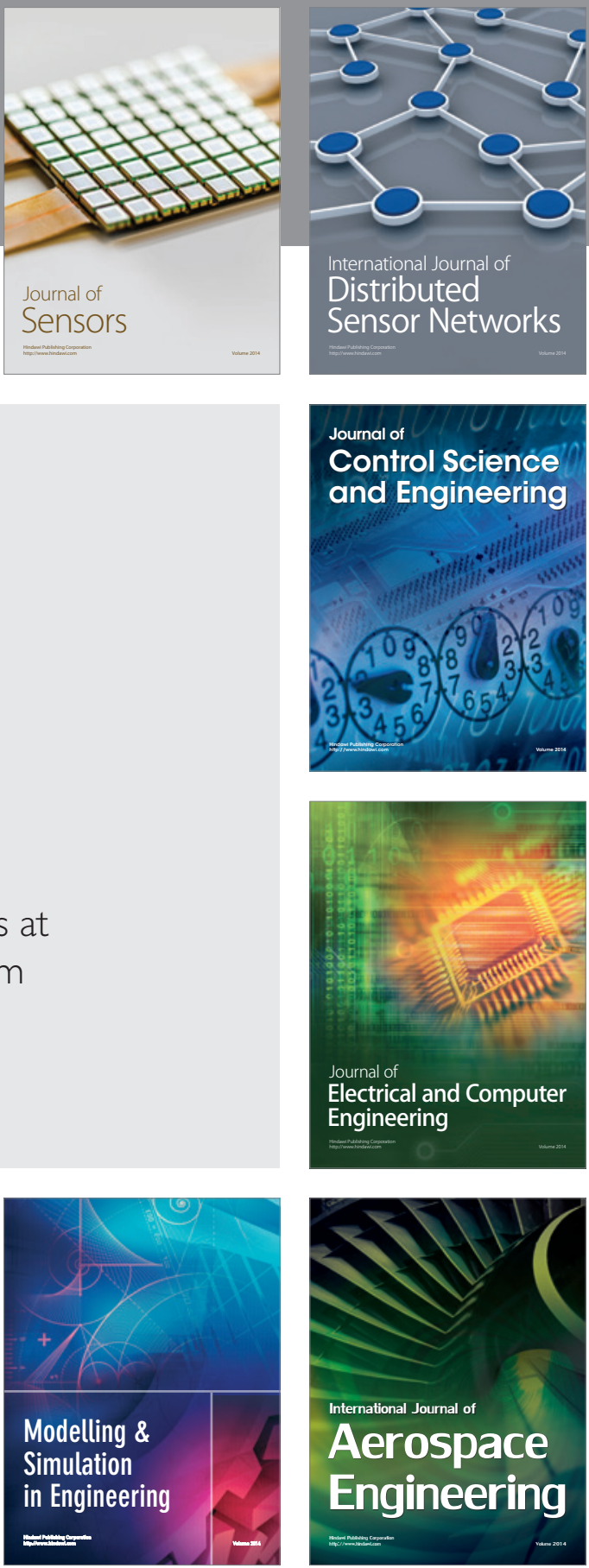

Journal of

Control Science

and Engineering
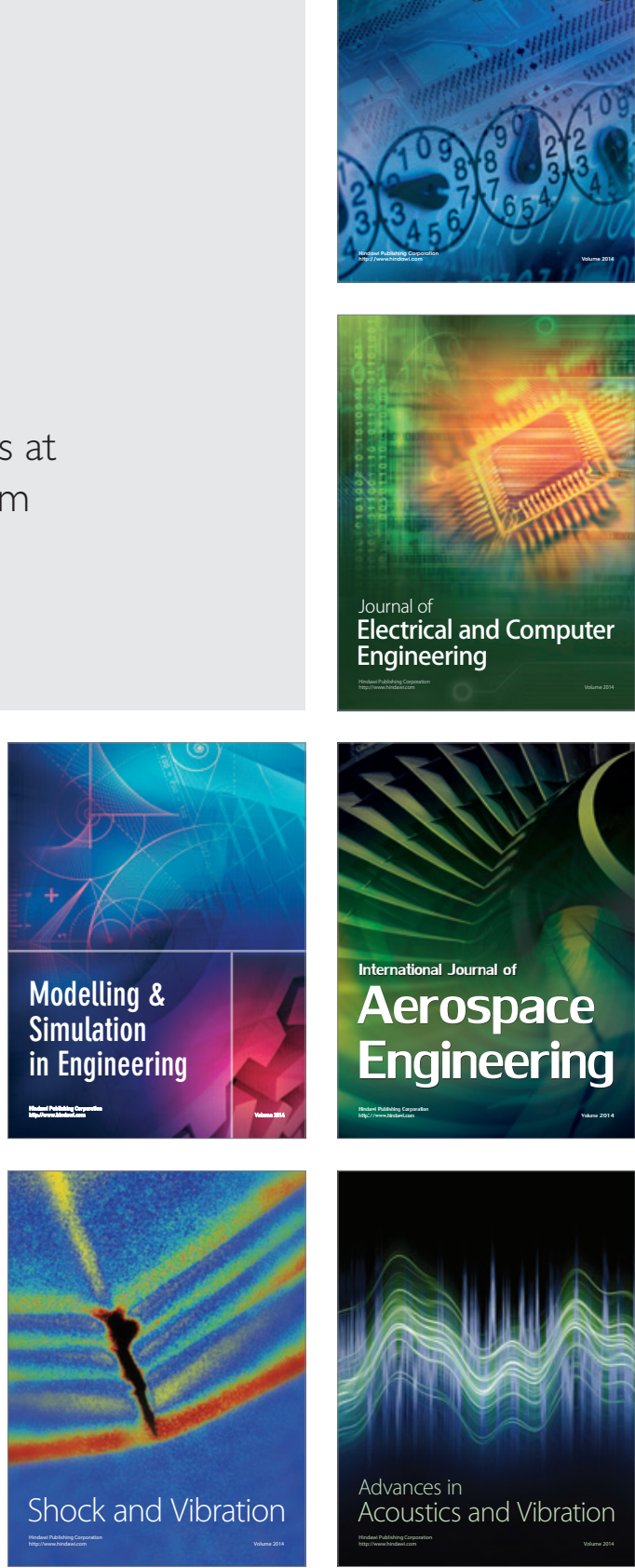